Europe's Journal of Psychology 2/2010, pp. 32-46

www.ejop.org

\title{
Organizational commitment in Spanish and Italian volunteers: A comparative study
}

\author{
María Celeste Dávila \\ Complutense University of Madrid \\ Juan Francisco Díaz-Morales \\ Complutense University of Madrid
}

Marianna Pasquini

University of Florence

Marco Giannini

University of Florence

\section{Abstract}

Recently, it has been demonstrated that attitudes toward an organization impact upon sustained volunteerism. We compared Spanish and Italian volunteers using the Organizational Commitment Questionnaire (OCQ) and then investigated how organizational commitment related to the intention to remain in the organization. Confirmatory and multiple-groups confirmatory factor analysis were used to assess factor structure and structural invariance across the two countries. The results showed that a two-factor model of organizational commitment best characterized the OCQ structure for both samples. Factorial invariance across countries was demonstrated for both factors (Involvement and Acceptance). When we examined the relations between each invariant factor and the intention to remain, Acceptance was the factor that accounted for more variation in the intention to remain.

Key words: prosocial behavior, cross-cultural studies, volunteerism, attitudes, organizational commitment. 
Introduction

Volunteerism is a social phenomenon that has been defined as "prosocial action in an organizational context, which is planned and that continues for an extended period" (Penner, 2002, see Penner, Dovidio, Piliavin and Schroeder, 2005, p. 375). Two main questions can be invoked in its study: What factors contribute to the decision to become a volunteer? And, what factors account for the maintenance of volunteerism?

The purpose of the present study was to address the second question and to determine how best to promote the retention of volunteers within an organization. A high percentage of people who decide to become volunteers do not maintain their commitment for very long, and drop out of the organization they have joined (Dávila, Vecina \& Chacón, 2005; Dávila, 2007; McCurley \& Lynch, 2005). The continuity of volunteers in organizations can be affected by non-controllable factors such as disease, family or labour problems, and death, among others. But in many circumstances, volunteers leave an organization in part because of organizational management issues, for example, low satisfaction with volunteer work conditions and bad personal relationships with work mates. This attrition associated with controllable factors is called dysfunctional turnover (Jamison, 2003). From a psychosociological perspective, diverse theoretical models have been developed to explain volunteer retention and to prevent dysfunctional turnover, among other objectives.

Prediction of volunteer retention

Presently, the two models that have been most influential in predicting volunteer continuity have been the Volunteer Process Model (Omoto \& Snyder, 1995, 2002) and Role Identity Model of Volunteerism (Callero, Howard, \& Piliavin, 1987; Grube \& Piliavin, 1996; Piliavin \& Callero, 1991). In the first model, a series of antecedents variables are differentiated (disposition to help, motivations, and social support) that, along with two process variables (satisfaction and organizational integration), account for volunteer permanence. The second model is based on the idea that being a volunteer for a long period of time increases one's commitment towards the organization, which, in turn, leads to an increase of actions favouring the organization. This leads people to assume the role of volunteer as part of their personal identity, which in turn leads to continuing to perform volunteer behaviors. Since this role is assumed, performing behaviors that are coherent with their identity is reinforcing for the individuals. These theoretical models are congruent in many aspects, but the Omoto and Snyder model concentrates more on intrapersonal 
variables, whereas Piliavin and associates' model pays more attention to social roles and social context (Penner et al., 2005).

Since the inception of these models, other theoretical models deriving from them have been developed: Davis, Hall, and Meyer's (2003), for example. Among the most recent models, we highlight the Conceptual Model of Sustained Volunteerism (Penner, 2002), and the innovative model of Hart, Atkins, and Donnelly (2004) (Penner et al., 2005), which attempts to integrate both sociological and psychological approaches to volunteering. From volunteerism research in Spain, we highlight the Basic Model (Dávila \& Chacón, 2004, Dávila \& Chacón, 2007) and the Three-stage Model of Volunteer's Duration of Service (Chacón, Vecina \& Dávila, 2007) aiming to explain the different factors that predict the duration of service over short or long periods of time.

Organizational commitment

In many theoretical models, organizational commitment predicts volunteers' permanence. Sometimes organizational commitment appears as an independent element, and other times as an element integrated into a broader category with other related concepts, such as job satisfaction. This broader category has been labelled as relationships with the organization (see Penner, 2002) or attitudinal variables (see Miller, Powell \& Seltzer, 1990).

In recent years, organizational commitment has emerged as a central concept in the study of work attitudes and behaviour (e.g., Mathieu \& Zajac, 1990; Meyer \& Allen, 1991), because organizational commitment is related to two very important variables: the intention to leave an organization and actual withdrawal behaviour (see Allen \& Meyer, 1996).

Porter, Steers, Mowday \& Boulian (1974) defined organizational commitment as the strength of an individual's identification with and involvement in an organization. For them, commitment is characterized by three factors: a strong belief in and acceptance of the organization's goals and values, a willingness to exert considerable effort on behalf of the organization, and a desire to maintain organizational membership. Their definition can be interpreted as reflecting affective commitment (Mowday, 1998): affective commitment results in situations where the employee or volunteer wants to continue his or her association with the organization (Dawley, Stephens \& Stephens, 2005). 
At the moment, most researchers believe that organizational commitment is a multidimensional attitude (Meyer, Allen \& Topolnysky, 1998). Lately, the Meyer and Allen (1991) model has dominated commitment research. These authors distinguish between affective commitment, continuance commitment (which refers to commitment based on the employee's recognition of the costs associated with leaving the organization) and normative commitment (which refers to commitment based on a sense of obligation to the organization) (Allen and Meyer, 1996).

The majority of organizational commitment studies have focused on remunerated personnel, but few studies have focused on volunteers (Dávila \& Chacón, 2003; DeChant, 2001; Miller et al., 1990; Pearce, 1993, for example). Many of theses studies about volunteerism have used the Organizational Commitment Questionnaire (OCQ) developed by Mowday, Steers \& Porter (1979); however, in recent years the questionnaire developed by Meyers and Allen (1996) has been employed, for example, in Grube and Piliavin (2000), Dawley et al. (2005), Stephens, Dawley and Stephens (2004), Boezeman and Ellermers (2007) and Van Vuuren, De Jong and Seydel (2008). Our research team has been adapting the Meyers and Allen's questionnaire to Spanish volunteers, but for the moment we have not achieved this. We have encountered several difficulties, for example with regard to normative commitment, the reciprocal nature of a working relationship may be more central to paid employees, as their relationship with the organization is more contractual than for volunteers. Regarding continuance commitment, the loss of important material or immaterial benefits and incentives will presumably be less prominent for volunteers and the perceived lack of alternatives is presumably also smaller for volunteers than for paid employees (Van Vuuren et al., 2008). On the other hand, the results of Van Vuuren et al. (2008) showed that volunteers had a significantly higher level of affective commitment to the organization than paid employees. For these reasons this study analyses the $O C Q$, that reflects affective commitment and previously we have had good results using it with Spanish volunteers. In any case, Allen and Meyer (1996) found a strong relationship between the OCQ and Meyers and Allen's Affective Commitment Scale.

Intention to continue

As was previously stated, the construct of organizational commitment has received much attention because it correlates with the intention to leave and actual withdrawal behaviour. In volunteerism, several studies find that organizational commitment is related with the intention to leave or continue with an organization, such as the studies of Miller et al. (1990), Dávila and Chacón (2007) and Grube and Piliavin (2000). Many researchers (for example, Fishbein \& Ajzen, 1975) have provided 
evidence that the intention to act is the best predictor of actually carrying out behaviours. In two meta-analyses (Randall \& Wolff, 1994; Sheppard, Hartwick \& Warshaw, 1988; see Lee, Piliavin \& Call, 1999), researchers found mean correlations of 0.53 and 0.45 between intention and behaviour over a broad range of behaviours. Randall \& Wolff did not find any significant effect for the time in relationship between intention and behaviour.

\section{Cross-cultural comparisons}

An important limitation of current studies is that the majority of studies about organizational commitment in volunteerism have been carried out in Anglo-Saxon countries. Relatively few studies about this subject can be found in Mediterranean countries, and there are even fewer cross-cultural studies. Although these countries share a western culture, there can be different cultural norms and values that affect the organizational attitudes and their relationship with relevant outcomes such as efficiency at work and withdrawal behaviour.

Cross-cultural comparisons are interesting because they address the question of whether the findings obtained in one country can be generalized to other countries. Here, we focus on a comparison between Spain and Italy. Both countries are Mediterranean and they are very similar in their standard of living. It would be very useful to have validated instruments to measure several constructs in volunteers in both countries and to analyze in depth the similarities and possible differences.

The rationale for our study was to investigate differences between Spanish and Italian volunteers. To this end, we analyzed a total sample of 408 volunteers from these two countries. We analyzed the factor structure of the $O C Q$ in Italy and Spain, as well as their partial factorial invariance (factor loadings). Before we could explore hypotheses about cultural differences in organizational commitment, it was necessary to demonstrate the factorial invariance of the $O C Q$. Differences between countries were then tested. When factorial invariance was found, we analyzed the relationship between organizational commitment and intention to remain in the organization over the course of the next year for each country. Although the relationship between organizational commitment and intention to leave or to remain has been identified and replicated in multiple studies, we looked for possible differences in magnitude of this relationship among countries. 
Method

Participants

Data were collected from volunteers in Italy and Spain. The combined sample ( $\mathrm{n}=$ 408) was primarily female (66.91\%), and age ranged from 16 to 81 years $(M=41.58$, $S D=17.91$ ). Participation was voluntary, unpaid and anonymous.

We collected dates only from volunteers that doing assistential activities to reduce the variability of type of volunteer activity. In previous studies we have found significant differences between types of volunteer activity with relation to the prediction of sustained volunteerism (Dávila \& Chacón, 2004; 2007).

Spanish participants: Two hundred twenty-four volunteers affiliated with 23 nongovernmental organizations participated in this study. There were 157 women and 67 men. The mean age was 37.17 years $(S D=17.42$, range $=16-81)$. Regarding educational level, $12 \%$ of participants had completed only primary studies, $31.2 \%$ secondary studies, and $53.6 \%$ university studies.

Italian participants: One hundred eighty-four volunteers affiliated with 26 nongovernmental organizations participated in this study. There were 116 women and 68 men. The mean age was 46.53 years $(S D=17.19$, range $=19-81)$. Regarding educational level, $32 \%$ of participants had completed only primary studies, $44 \%$ secondary studies, and $24 \%$ university studies.

Differences between samples: We found that Italian volunteers were significantly older than Spanish volunteers $(F(1,407)=28,473, p<0.01$ ) with a 1 (age) $\times 2$ (Italian and Spanish volunteers) analysis of variance (ANOVA). We did not find significant differences in the proportion of men $(Z=-1,750, p>0.05)$ or women $(Z=1,555, p>0.05)$ between the samples. However, we found significant differences between the samples with respect to the proportion of volunteers who attained various levels of education (proportions' differences in primary $(Z=-5,263, p<0.01)$, secondary $(Z=2,782, p<0.01)$ and university level $(Z=-6,434, p<0.01))$. In the Italian sample, there were proportionally more people with only primary and secondary level attainment, and in the Spanish sample, there were more individuals who had graduated from a university. 
Instruments

Organizational Commitment: The reduced version of the Organizational Commitment Questionnaire (OCQ), created by Mowday et al. (1979), was adapted by Dávila and Chacón for the Spanish population to address volunteerism (2003). It was adapted for use with Italian volunteers by Pasquini and Gianinni (unpublished research). This questionnaire was designed to measure the degree to which subjects feel committed to an organization. It includes items pertaining to the subject's perceptions concerning his loyalty toward the organization, his willingness to exert a great deal of effort to achieve organizational goals, and his acceptance of the organizational values (Porter et al., 1974). This questionnaire has nine items with a seven-point Likert-type response format, ranging from 1 (completely disagree) to 7 (completely agree). Examples of items are: "I am willing to put in a great deal of effort beyond that normally expected in order to help this organization be successful", "I find that my values and the organization's values are very similar", and "For me this is the best of all possible organizations for which to work". The internal consistency reliability (Cronbach's alpha) was 0.87 in the Spanish sample and 0.86 in the Italian sample.

Intention to remain: This was measured by a single item. This question asked the volunteers specifically about the probability of their continuing volunteer work within the organization after 1 year on a scale of 1 to 7 ( 1 meaning no probability, and 7 meaning maximum probability).

Procedure

The conditions of the questionnaire administration were agreed upon with each organization to cause the least possible interference in regular functioning. In some cases, a representative of the organization distributed and collected the questionnaires. In other cases, the representative provided a list of the volunteers' addresses, so we could send them the questionnaire together with a pre-paid envelope for its return. Finally, in other cases, the representative sent the questionnaire by e-mail to the volunteers and they sent it back, either by postal mail, e-mail, or fax to the organization representative or to the researchers.

Results

In order to test factorial structure and factorial invariance across countries, a multiple group confirmatory factor analysis with LISREL methodology (Jöreskog \& Sörbom, 1993) was used. The models were tested using a covariance matrix and each model 
was estimated using maximum likelihood. Model fit was based on several recommended criteria (Bentler, 1992): the chi-square test $\left(\chi^{2}\right)$, the comparative fit index (CFI > 0.90), the non-normed fit index (NNFI > 0.90), the goodness of fit index (GFI > 0.90), the root mean square error of approximation (RMSEA < 0.10), and the chi-square difference tests $\left(\Delta \chi^{2}\right)$.

Prior to determining if the organizational commitment remains invariant across countries, it was necessary to examine the factor structure of the measure separately in each country. We found that a two-factor baseline model was estimated separately for the Italian and Spanish samples: the first factor was labeled as "Acceptance" and reflected the individual's acceptance of organization's goals and values (items 2, 4, 5, 6, and 7); the second factor was named "Involvement" because it indexed and individual's propensity to exert considerable effort on behalf of the organization (items 1, 3, 8 and 9). For all models, each item was specified to load on a single factor, the factor loading for each latent construct was fixed to 1 , and factors were allowed to correlate. Preliminary single group analyses showed a reasonable baseline model for both Italian and Spanish samples. The two-factor congeneric measurement model provided marginal explanation for the Italian sample, $\chi^{2}=67.47, \mathrm{df}=26, \mathrm{RMSEA}=0.09, \mathrm{NNFI}=0.93, \mathrm{CFI}=0.95, \mathrm{GFI}=0.92$, and marginal explanation for the Spanish sample, $\chi^{2}=56.32, \mathrm{df}=26, \mathrm{RMSEA}=0.08, \mathrm{NNFI}=$ 0.93, $\mathrm{CFI}=0.95, \mathrm{GFI}=0.92$.

Next, a model was estimated simultaneously for the Italian and Spanish sample to provide a baseline model against which to compare more restrictive models. The first hypothesis tested was that the two-factor structure is invariant across countries (model 1). The results of this analysis showed that a two-factor solution represents a reasonable fit to the data, $\chi^{2}=123.79, \mathrm{df}=52, \mathrm{RMSEA}=0.09, \mathrm{NNFI}=0.93, \mathrm{CFI}=0.95$. In the subsequent model, all estimable factor loading parameters were constrained as equal across groups as a test of measurement invariance (model 2). Since the difference in $\chi^{2}$ was not significant $\left(\Delta \chi^{2}(7)=13.9\right)$, the hypothesis of an invariant pattern of factor loadings was considered to be tenable.

The results of the multigroup analysis to test if the groups have different mean levels of organization commitment constructs showed that the Spanish sample endorsed lower levels than did the Italian sample for Acceptance $(M=-0.38$; $S E=0.14$; $t$-value $=-3.37, \mathrm{p}<0.05)$ and Involvement $(M=-0.20 ; \mathrm{SE}=0.09 ; \mathrm{t}$-value $=-2.12, \mathrm{p}<0.05)$.

The means and standard deviations for each factor are presented in Table 1. The data were also analyzed with a 2 (invariant factors) x 2 (volunteers' samples) ANOVA. There were significant differences in Involvement $(F(1,407)=3.876, p=0.05)$ 
and Acceptance $(F(1,407)=20.337, p<0.01)$. In the two cases, Italian volunteers reported greater commitment levels.

Table 1: Summary of Descriptive Statistics for Invariant Factors

\begin{tabular}{ccccc}
\hline \multirow{2}{*}{ Participants } & \multicolumn{2}{c}{ Involvement } & \multicolumn{2}{c}{ Acceptance } \\
\cline { 2 - 5 } & $M$ & SE & $M$ & SE \\
\hline Spanish volunteers & 4.75 & 1.10 & 5.70 & 1.02 \\
Italian volunteers & 5.00 & 1.37 & 6.15 & 0.92 \\
\hline
\end{tabular}

To examine the relationships between each invariant factor and intention to remain, we performed two multiple regression analyses, one for each volunteer group. The intention to remain was regressed on the two invariant factors, Involvement and Acceptance, and educational level and age. These analyses were conducted controlling for age and educational level as potential confounders because we found significant differences between the samples with respect to these variables.

In Spanish volunteers, Involvement and Acceptance were significant predictors for the intention to remain. Acceptance accounted for $23 \%$ of variation in intention to remain, and Involvement accounted for an additional $3.1 \%$ of variation in intention to remain. In Italian Volunteers, Acceptance was the only significant predictor for intention to remain; it accounted for $25.4 \%$ of intention to remain (see Table 2). Neither age nor educational level were significant predictors for the intention to remain.

Table 2: Summary of Multiple Regression Analyses of Intention to Remain ( $N=408$ )

\begin{tabular}{cccc}
\hline Factors & $\mathrm{B}$ & Partial F & $\mathrm{R}^{2}$ \\
\hline $\begin{array}{ccc}\text { Spanish Volunteers } \\
\text { Acceptance }\end{array}$ & 0.383 & $51.116^{* *}$ & 0.233 \\
Involvement & 0.356 & $30.652^{* *}$ & 0.031 \\
Italian Volunteers & & & \\
Acceptance & 0.691 & $63.202^{* *}$ & 0.254 \\
\hline Note ${ }^{* *}$ P $<01$ & &
\end{tabular}

Note: ${ }^{* *} p<.01$

Discussion

The purposes of this study were to analyze the factorial invariance of the $O C Q$ in samples of Spanish and Italian volunteers, and to analyze the relationships in each sample between organizational commitment and intention to remain active in the 
organization since these would help to determine how best to promote the retention of volunteers within an organization.

First, we discussed the factor structure of our models. A two-factor structure of the OC was obtained for both the Spanish and Italian samples. "Involvement" and "Acceptance" were invariant (with respect to factorial form and loadings) across countries. The factor labeled as Acceptance reflected the individual's acceptance of an organization's goals and values, and the factor named Involvement reflected the individual's propensity to exert considerable effort on behalf of the organization.

Previous analyses examining the factor structure of $O C Q$ have resulted in a singlefactor solution and have suggested a single common underlying construct. In those cases where two factors emerged, the eigenvalues associated with the second factor only narrowly exceeded 1, and the percentage of common variance explained by the second factor was much lower than the percentage of variance associated with the first factor (Mowday et al., 1979; Dávila \& Chacón, 2003). In volunteerism research, only Dávila, Chacón \& Arias (2005) found results that suggested the existence of two discrete factors. The findings obtained in the present study contribute new data about OCQ's factorial structure in volunteers and contribute to the cross-cultural validity of the $O C Q$ in volunteerism's research. In this study, there is evidence suggesting that the $O C Q$ does not evaluate a unidimensional attitude in the volunteer population. It is necessary to study the volunteer's organizational commitment in depth and to analyze differences with remunerated personnel, but it is possible that these differences will be related to a greater relevance of acceptation of the organization's goals and values to develop organizational commitment in volunteers. In many cases, the volunteering is carried out during leisure time and other personal responsibilities (paid employment, family, etc.) can limit the propensity to exert additional effort on behalf of the organization.

Second, we discussed the relations between commitment and intention to remain. The findings show that commitment accounted for a reduced percentage of variance of intention to remain in Italian and Spanish volunteers. It is very probable that other variables, such as job satisfaction or role identity for example, can also to account for the intention to continue. Taking these constructs into account could increase the percentage of explained variance in the intention to continue (Penner, 2002). Also, we must take into account that volunteers' attitudes do not necessarily imply the corresponding behavioural consequences, for example, Laczo and Hanisch (1999) suggest that commitment may have less impact on the intentions of volunteers to stay with the organization compared to paid employees (see in Van Vuuren et al., 2008). Another possibility is that the OCQ is not able to suitably assess 
organizational commitment in volunteers, or that it will be necessary to take additional indicators into account in order to increase the explanatory capacity of this instrument. In this sense, Dávila and Chacón (2007) were able to account for a $43 \%$ of intention to remain variance when they used other indicators. Several measurements used by Omoto and Snyder (1995) to study integration with the organization (specifically, the items that refer to acceptance of the philosophy, goals, and purposes of the organization), were added. It will be interesting to examine if these additional indicators can increase the percentage of explained variance for intention to remain in Italian volunteers.

Another important result is that factor Acceptance played a more significant role than factor Involvement in the prediction of intention to continue in the volunteers of both countries. For Italian volunteers, Acceptance was the only significant predictor for the intention to remain. In this sense, if the organizations want to promote sustained volunteerism in Italy and Spain they must recruit and select volunteers with a strong belief in and acceptance of the organization's goals and values, or to use management strategies to promote this acceptance through training or supervision, for example. Understanding the process through which volunteers become committed to organizations and how that process can be managed would be of considerable benefit for both volunteers and managers.

The last outcome to note is the Italian volunteers' higher score on organizational commitment when compared to Spanish volunteers. I would argue that this greater commitment is justified by the age of the Italian volunteers in the present research, they were older than the Spanish sample. Life course studies (Oesterle, Jonson \& Mortimer, 2004) have shown that the meaning of roles and activities change over the life course. For example, the adoption of new roles can limit the available time and energy for volunteerism in adulthood. Parenthood is a role of particular importance in this stage. When children are in nursery education, the parent's demands are very extensive, and there are fewer opportunities to connect with other people or organizations outside of the family and work contexts. When children grow and become involved with new activities, this promotes the integration of parents into their community (Oesterle, Jonson \& Mortimer, 2004). In this way, if we pay attention to the mean age of Spanish volunteers ( $M=37.17$ years) and mean age of Italian volunteers ( $M=46.53$ years), we can conclude that Italian volunteers are less likely to have small children. Therefore, it is more probable that they have enough time and energy to engage in and have a greater commitment to other activities, e.g. volunteerism and the context where it takes place: the organization. 
Limitations and Perspectives for Future Research

The present study has several limitations. First, the use of a single item for measuring intention to remain is a major issue because single-item measures have an unknown reliability. Second, we cannot ascertain how representative our sample was of the greater population of volunteers in the two countries. Third, we studied volunteers who performed assistential activities. It will be necessary to investigate if it is possible to generalize the findings of the present study to other types of volunteerism (e.g. environment volunteerism). Fourth, it will be necessary to complete more crosscultural studies to demonstrate that the factorial structure of $\mathrm{OC}$ is similar in volunteers in other countries.

\section{References}

Allen, N.J. \& Meyer, J.P. (1996). Affective, continuance and normative commitment to the organization: An examination of construct validity. Journal of Vocational Behavior, 49, 252-276.

Bentler, P. M. (1992). On the fit of models to covariance and methodology to the Bulletin. Psychological Bulletin, 112, 400-404.

Boezeman, E.J. \& Ellermers, N. (2007). Volunteering for Charity: Pride, respect, and the commitment of volunteers. Journal of Applied Psychology, 92(3), 771-785.

Callero, P., Howard, J.A. \& Piliavin, J.A. (1987). Helping behaviour as role behaviour: disclosing social structure and history in the analysis of prosocial action. Social Psychology Quarterly, 50 (3), 247-256.

Chacón, F., Vecina, M.L. \& Dávila, M.C. (2007). The three-stage model of volunteers' duration of service. Social Behavior and Personality: An international Journal, 35 (5), $627-$ 642.

Dávila, M.C. (2007). Abandono del voluntariado. Foro Internacional sobre Comunicación y Voluntariado. Comunicación e Ciudadanía, 5.

Dávila, M.C. \& Chacón, F. (2003). Adaptación de instrumentos para la evaluación de aspectos organizacionales en ONG's. Revista de Psicología del trabajo y de las organizaciones, 19 (2).159-179. 
Dávila, M.C. \& Chacón, F. (2004). Factores psicosociales y tipo de voluntariado. Psicothema, 16 (4), 639-645.

Dávila, M.C. \& Chacón, F. (2007). Prediction of Longevity of Volunteer Service: A Basic Alternative Proposal. Spanish Journal of Psychology, 10 (1), 115-121.

Dávila, M.C., Vecina, M.L. \& Chacón, F. (2005). Análisis de las tasas de abandono en una muestra de voluntarios y causas más frecuentes. J. Romay \& R. García (Eds.). (2005). Psicología Social y Problemas Sociales. Vol. 5. (pp. 205-212). Madrid: Biblioteca Nueva.

Dávila, M.C., Chacón, F. \& Arias, A. (2005). Adaptación del organizational commitment questionarie al voluntariado español. Iberpsicología, 10.1.3.

Davis, M.H., Hall, J.A., \& Meyer, M. (2003). The first year: Influences on the satisfaction, involvement and persistence of new community volunteers. Personality and Social Psychology Bulletin, 29, 248-260.

Dawley, D.D., Stephens, R.D. \& Stephens, D.B. (2005). Dimensionality of organizational commitment in volunteer workers: Chamber of commerce board members and role fulfilment. Journal of Vocational Behavior, 67(3), 51 1-525.

DeChant, G.L. (2001). A Study of prosocial personality characteristics \& leadership traits involving PTA volunteers. Undergraduate Journal of Psychology, 14.

Fishbein, M. y Ajzen, I. (1975). Belief, Attitude, Intention y Behavior: An Introduction to Theory and Research. Reading, MA: Addison-Wesley.

Grube, J. \& Piliavin, J.A. (1996). Role-identity, organizational commitment, and volunteer performance. Paper presented at the annual meeting of Society for the psychological study of social issues. Miami: Ann Albor.

Grube, J.A. \& Piliavin, J.A. (2000). Role Identity, organizational experiences, and volunteer performance. Personality and Social Psychology Bulletin, 26 (9), 1108-1119.

Jamison, I.B. (2003). Turnover and retention among volunteers in human service agencies. Review of Public Personnel Administration, vol. 23(2), 114-132.

Jöreskog, K.G. \& Sörbom, D. (1993). Lisrel 8: Structural equation modeling with the simplis command language. Hillsdale, NJ: Scientific Software International.

Lee, L., Piliavin, J.A. \& Call,V.R.A. (1999). Giving time, money and blood: Similarities and differences. Social Psychology Quarterly, 62(3), 276-290. 
Mathieu, J.E. \& Zajac, D.M. (1990). A review and meta-analysis of antecedents, correlates, and consequences of organizational commitment. Psychological Bulletin, 108(2), 171-194.

McCurley, S. \& Lynch, R. (2005). Keeping Volunteers: A Guide To Retention. Philadelphia, PA.: Fat Cat Productions.

Meyer, J.R. \& Allen, N.J. (1991). A three-component conceptualization of organizational commitment. Human Resource Management Review, 1, 61-89.

Meyer, J.P. Allen, N.J. \& Topolnytsky, L. (1998). Commitment in a Changing world of work. Canadian Psychology, 39(1-2), 83-93.

Miller, L.E., Powell, G.N. \& Seltzer, J. (1990). Determinants of turnover among volunteers. (1990). Human relations, 43, 901-917.

Mowday, R.T. (1998). Reflections on the study and relevance of organizational commitment. Human Resource Management Review, 8(4), 387-401.

Mowday, R.T., Steers, R.M., \& Porter, L.W. (1979). The measurement of organizational commitment. Journal of Vocational Behavior, 14, 224-247.

Oesterle, S., Jonson, M.K. \& Mortimer, J.T. (2004). Volunteering during the transition to adulthood: A life course perspectiva. Social Forces, 82 (3), 1123-1149.

Omoto, A. M. \& Snyder, M. (1995). Sustained helping without obligation: motivation, longevity of service, and perceived attitude change among AIDS volunteers. Journal of Personality and Social Psychology, 68 (4), 671-686.

Omoto, A.M. \& Snyder, M. ( 2002). Considerations of community: the context and process of volunteerism. American Behavioral Scientist, 45, 846-886.

Pearce, J.L. (1993). Volunteers: The organizational behavior of unpaid workers. London: Routledge.

Penner, L.A. (2002). Dispositional and organizational influences on sustained volunteerism: An interactionist perspective. Journal of Social Issues, 58(3), 447-467.

Penner, L.A., Dovidio, J.F., Piliavin, J.A. \& Schroeder, D.A. (2005). Prosocial Behavior: Multilevel pespectives. Annual Review of Psychology, 56, 365-392. 
Piliavin, J.A. \& Callero, P.L. (1991). Giving Blood: The development of an Altruistic Identity. Baltimore: Johns Hopkins University Press.

Porter, L.W., Steers, R.M., Mowday, R.T. \& Boulian, P.V. (1974). Organizational commitment, job satisfaction and turnover among psychiatric technicians. Journal of Applied Psychology, 59 (5), 603-609.

Stephens, R.D., Dawley, D.D. \& Stephens, D.B. (2004). Commitment on the board: A model of volunteer directors' levels of organizational commitment and self-repeorted performance. Journal of Managerial Issues, 16(4), 483-504.

Van Vuuren, M., De Jong, M.D.T. \& Seydel, E.R. (2008). Commitment with or without a stick of paid work: Comparison of paid and unpaid workers in a nonprofit organization. European Journal of Work and Organizational Psychology, 17(3), 315-326.

About the authors:

María Celeste Dávila

Ph.D on Psychology and lecturer in Social Psychology Department (Faculty of Politic Sciences and Sociology. Complutense University of Madrid. Spain). Her main research topics are about prosocial behavior.

Address for correspondence: mcdavila@cps.ucm.es

Juan Francisco Díaz-Morales

Ph.D on Psychology and lecturer in Department of Individual Differences and Work Psychology (Faculty of Psychology. Complutense University of Madrid. Spain). His main research topics are procrastination, temporality, and cronopsychology.

Marianna Pasquini

Graduate on Psychology and collaborator with Psychology Department (Faculty of Psychology. University of Florence. Florence).

Marco Giannini

Researcher on Psychology in Psychology Department (Faculty of Psychology. University of Florence. Florence). His main research topic is about methodology in psychology research. 